\title{
ANNOUNCEMENT
}

International Year of

International Year of
CHEMISTRY

2011

\section{严 Springer}

the language of science

\section{Springer in the International Year of Chemistry 2011}

As a leading international publisher in Chemistry, Springer enthusiastically supports the goals of the International Year of Chemistry 2011. The objectives of IYC include enhancing the public appreciation of chemistry in meeting world needs and also celebrating the achievements of chemistry and its contribution to the well-being of mankind. As a step towards these objectives, Springer constantly develops innovative ways to bring information about chemistry and related sciences to a wide audience, not only of specialists in a given area, but also to researchers and teachers in other areas, students and others. Increasingly online media play the key part in worldwide dissemination of Springer's publications. Springer's online Chemistry and Materials Science package provides 24/7 access to 200 peer-reviewed journals and over 2,000 eBooks, with some 200 new eBook titles added per year. Additionally, Springer offers publications in the area of chemical and molecular sciences that are included in Springer's other eBook collections in areas such as life sciences, medicine, environment and energy. Overall, Springer currently offers over 2,000 online journals and 40,000 ebooks.

Springer has a range of new products to support students and young scientists.

- A newly launched book series "Lecture Notes in Chemistry" will make information at the forefront of research accessible to advanced students.
- Springer Theses, publishes exceptional theses from leading research institutions around the world, providing an international forum for outstanding young scientists at the start of their careers.

- Students and staff of institutions in North America and several European countries, that have purchased one or more Springer eBook collections, are now offered the opportunity to order their personal printed copy of an eBook at a fixed price of 24.95 USD/EUR. These socalled MyCopy books are black-and-white, paperback, print-on-demand books, and can be ordered directly from SpringerLink.

Through its extensive range of journals, books, reference works and databases, Springer plays a leading part in the broad dissemination of information on chemistry and its applications in all areas of human activity.

Dr. Sonia Ojo

Senior Publishing Editor, Springer 